\title{
Topical Medication of Wound May Mislead the Medico-Legal Judgment
}

\author{
Abdou.Rania. Helmi ${ }^{1}$, Shereen.M. Mahmoud ${ }^{2}$ \\ 1, 2: Department of Forensic Medicine and Toxicoloy,Faculty of Veterinary \\ Medicine, Suez Canal University, Egypt. \\ Shereen.M.Mahmoud: rinamoh2002@hotmail.com \\ Abdou.Rania.Helmi* : rania-vet@ hotmail.com
}

Corresponding author: Rania Helmi Abdou*, Department of Forensic

Medicine and Toxicology, Faculty of Veterinary Medicine, University of

Suez Canal, Ismailia 41522, Egypt, Email: rania-vet@ hotmail.com, ORCID

iD: https://orcid.org/0000-0003-0135-7557

\begin{abstract}
Wound is a great issue that is very important in forensic medicine reports with its great medico-legal importance through inspecting wound characters and estimating its incidence time. In this study, twenty-seven male albino rats (200-220 gm) were randomly divided into three groups $(n=9)$ to study the effects of topical wound dressing on wound healing. Group I (positive control group): wound surface was treated with saline while, groups II and III were treated daily with a thin film of panthenol gel and helarium cream, respectively. Pieces of skin containing the wound area were taken after 1, 7 and 14 days to estimate the wound healing process. Wound area was examined macroscopically and microscopically using transmission electron microscope. The obtained results revealed that both panthenol and helarium enhanced wound healing process compared with control group; there was significant wound area shrinkage after 7 days of panthenol treatment. We conclude that wound healing may be accelerated by using some medications which consequently, leads to inaccurate forensic judgment concerning wound age.
\end{abstract}

Keywords: Forensic, Wound healing, Losing wound, Transmission electron microscope, Panthenol, Helarium.

\section{Introduction:}

Skin is the body's most extensive organ that protects the body against numerous harmful agents (Cohen et al., 2005). The integrity of the skin plays an important role in maintaining physiological homeostasis of the body (Morton and Phillips, 2016).

Wound is of a great issue that is very important in forensic medicine with its great medico-legal importance through understanding wound characters, estimating its age 
and differentiation between antemortem and post-mortem wounds (Ohshima, 2000 and Abbas et al., 2019).

The pathophysiology of the wound healing is a main point in the forensic investigation as it focuses on estimating wound vitality and evaluating the wound age (Grellner and Madea, 2007 and $\mathrm{Na} \mathrm{Li}$ et al., 2018).

The stages of wound healing involve homeostasis and inflammation, proliferation, differentiation and reformation. Macrophages regulate the cell proliferation, matrix formation, and angiogenesis by releasing mediators. Proliferation step remains about 12-14 days. During this step, tissue integrity is restored and established. Fibroblasts and endothelial cells are the last cell population which is infiltrated into the site of healing wound (Cohen et al., 2005).

Naturally originated complex mixtures have countless beneficial effects on wound healing and contain different chemicals that have antioxidant, anti-inflammatory and cell synthesis-modulating properties (Eshghi et al., 2010).

Panthenol is the alcohol analogue derivative of pantothenic acid, the pro-vitamin of the B-complex group that is an essential constituent of skin and hair. When applied topically, panthenol is transformed into pantothenic acid, a constituent of coenzyme A and holo-fatty acid synthase that is important element to normal epithelial function and has anti-inflamatory and antioxidant activities (Gehring and Gloor, 2002, Wan Li-Mei et al., 2016 and Abbas et al., 2019).

Panthenol has anti-inflammatory properties and usually used in topical formulations to improve and maintain good skin conditions, treatment of skin disorders and enhances healing process. Topical use of panthenol increases fibroblast proliferation and accelerated re-epithelialization in wound healing (Biro et al., 2003).

Helarium cream ${ }^{\circledR}$ is composed of honey, propolis, zinc oxide and chamomile. Propolis was used as a traditional medication from $300 \mathrm{BC}$ because of its antibacterial, antiinflammatory, antiseptic and antioxidant properties (Toreti et al., 2013, Sforcin, 2016, Sforcin et al., 2017 Sung et al., 2017 and Veiga et al., 2017).

Researchers proved the healing activities of propolis on tissue repairing and regeneration of injury; these are owing to its immunemodulatory, anti-inflammatory and antimicrobial characters as well as it accelerates formation of collagen fibers (Parolia et al., 2010, Kuropatnicki et al., 2013, Martinotti and Ranzato, 2015 and Sforcin, 2016).

Chamomile is one of the oldest medicinal plants that widely used in various healing applications (Astin et al., 2000). Chamomile has been used for many decades in healing purposes as anti-inflammatory and 
antioxidant agent. It also, used to treat wounds, ulcers, eczema, skin irritations, bruises, burns, rheumatic pain, hemorrhoids, mastitis and other illnesses (Awang-Dennis et al., 2006).

Topical application of chamomile enhances wound healing by faster epithelialization and increased rate of wound contraction (Nayak et al., 2007).

Zinc is an essential trace element that plays significant roles in immune function and wound healing (Roohani et al., 2013). Zinc-dependent proteins are necessary within cells for antioxidant defense (Pawlaket al., 2012).

Honey has been used as a wound dressing for centuries for its efficacy in healing process; it stimulates the immune response leading to enhancement of tissue growth for wound repair and suppresses inflammation (Molan and Rhodes, 2015). Honey is syrup of plants nectars that is rich in carbohydrates. Honey has been traditionally used in dressing burns, infected and non-healing wounds and ulcers (Zumla and Lulat, 1989, Wijesinghe et al., 2009 and Jull et al., 2013). Many researches indicated that the healing effect of honey is due to antibacterial, antiviral, anti-inflammatory and antioxidant abilitieas of its components (Yaghoobi et al., 2013).

These products are cheap, available and commonly used consequently, the majority of wounds those would be examined nowadays will be treated or at least with attempts of treatment.

Estimating wound age is a critical issue in forensic medicine. Wound healing may be accelerated by using topical medications and this leads to improper forensic decision concerning wound age. Therefore, the aim of this study was to estimate the effects of topical preparations (panthenol and helarium) on wound healing process of lose wound model in rats.

\section{Materials and Methods: \\ Drugs:}

Helarium cream ${ }^{\circledR}$ (honey, propolis, zinc oxide and chamomile), Bionorica company and panthenol gel® (D. panthenol 5\%), Merckle company were purchased from local pharmacy.

\section{Experimental animals:}

Twenty-seven male albino rats (average body weight 200-220g) were purchased from the animal breeding unite, Faculty of veterinary medicine, Suez Canal University, Ismailia. Rats were kept in stainless steel cages under proper environmental conditions of temperature $25-28^{\circ} \mathrm{C}$ with $12-\mathrm{hr}$ light/dark cycle and leave to acclimatize for one week. Skin and hair of the animals were examined and all had normal skin and hair. Animals were fed a commercial rodent diet and received water $a d$ libitum. Before surgical interventions, rats were anesthetized 
by intra-peritoneal ketamine / xylasine anesthesia $(50 \mathrm{mg} / \mathrm{kg}$ body weight ketamine and $6 \mathrm{mg} / \mathrm{kg}$ body weight xylazine) (Hall et al., 2001) and the skin was shaved.

\section{Wound model:}

Full thickness skin wounds (losing wound) were surgically created $(0$ day) on the back of rats under aseptic conditions by $5 \mathrm{~mm}$ biopsy punch (Figure

1).

\section{Experimental design:}

Animals were randomly divided into three groups $(\mathrm{n}=9)$ as follow:

- Group I (positive control group): wound surface was treated with saline.

- Group II (panthenol group): panthenol was topically applied daily as a thin film for 14 days.

- Group III (helarium group): helarium was topically applied daily as a thin film for 14 days.

After proper anesthesia, pieces of skin containing the wound area were taken after 1,7 and 14 days to estimate the wound healing activities.

\section{Estimating wound dimensions:}

The wound area and contraction percentage were photographed and scaled according to the technique described by Langemo et al., (2008) and Chang et al., (2011).

Transmission electron microscope examination:
Four blocks $1 \times 2 \mathrm{~mm}$ were taken from each sample and fixed for $24-$ $48 \mathrm{~h}$ in 5\% cold glutaraldehyed immedialy after dissection. The specimens were then washed in cacodylate buffer ( $\mathrm{pH}$ 7.2) $3-4$ times for 20 minutes every time and post fixed in $1 \%$ osmium tetroxide for 2 hours, after that washed in the same buffer four times. Dehydration by ascending grades of alcohol (30 $-50-70-90$ and $100 \% 2$ hours) of each block were done and embedded in epon-araldite mixture according to the protocol of electron microscope unit, Assiut University (Bozzola and Russell, 1991). From the embedded blocks semi-thin sections by LKB ultra-microtom in thickness of $0.5-1$ micron were prepared for orientation of the tissue and photographed by sc30 Olympus camera and then ultrathin sections in thickness of $500-700$ A were made using leica AG ultramicrtome and contrasted in uranyl acetate and lead citrate then examined by JEM 100 CXII electron microscope at $80 \mathrm{KV}$ and photographed by $\mathrm{CCD}$ digital camera Model XR- 41.

\section{Statistical analysis}

Wound area was compared between different groups using SPSS software (version 16; SPSS Inc., 2007, Chicago, Ill., USA). One-way ANOVA was done followed by post hook Fishers (Steel and Torrie, 1981). 


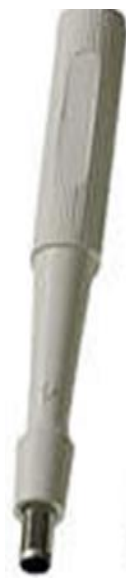

Figure (1): losing wound

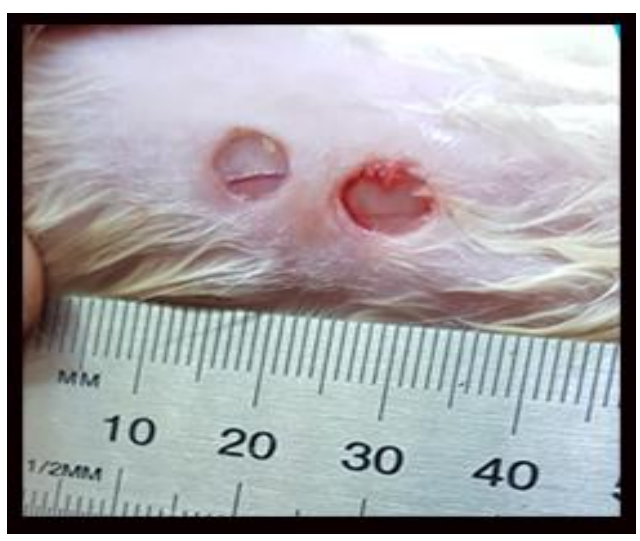

\section{Results:}

Macroscopic findings of wound healing

Tables (1\&2) and figure (2) showed the macroscopic appearance and wound areas $\left(\mathrm{mm}^{2}\right)$ after 1,7 and 14 days of treatment in the three experimental groups.

At zero and one day of treatment, there were no significant differences between the three groups while, after 7 and 14 days panthenol produced significant decreases in wound area in comparison with helarium and control groups. Helarium application did not significantly decrease the wound area all over the experimental period compared with control.

\section{Microscopical findings:}

The healing progress of the losing wound after $7 \& 14$ days is showed in figures $3 \& 4$.

After one day of treatment, the light and electron micrographs showed slight differences between the three groups. Light micrograph showed presence of coagulated structure less material on the surface covering the area of the wound and the epidermis and dermis appeared edematous and heavily infiltrated with neutrophile cells, coagulated plasma, RBC, s appears either in the wound gap or in the tissue edges of the wound (Toluidine blue stain). Electron micrograph showed blood vessels dilated filled with blood contain RBCs, neutrophils, and blood plasma also, edema and lysosomes were present in the dermis.

After 7 days, light micrograph examination of the control group showed partial healing of the epidermis by thin keratinized striated squamus epithelium formed by 3 to 5 cell layers. Electron micrograph showed regenerated epidermis formed by basal cell layer of cuboidal type having large vesicular nucleus and cytoplasm rich with cell organelles as well as 
wide intercellular spaces. The stratum granulosium and lucedium having variable size electron dens keratohyaline granules and thin laminated keratin layers.

In panthenol group, light micrograph of of the wound site showed the epidermal epithelium proliferated and extend from the edges of the wound under the coagulated and reacted cellular infilteration and above the dermal connective tissue. Electron micrograph showed the regenerated epidermis formed by lamellated keratin layers and the cells of stratum lucidum contain electron dens hyaline granules. There was infiltration of the inflammatory cells mostly neutrophils between the epidermal cells, the basal cells of the epidermis appeared active having large vesicular indented nucleus containing large nucleolus and the cytoplasm rich with cellular organelles also the intercellular space dilated and edematous.

In helarium group, light micrograph showed presence of structure less deeply stained material above the regenerated epidermal epithelium with presence of inflammatory cellular infiltration and the basal cells of the epidermis proliferated with dilatation of the intercellular spaces. The blood vessels of the dermis were dilated and congested. Electron micrograph showed heavy inflammatory cell infiltration mostly neutrophils and macrophages containing variable size spherical electron dens lysosomes and phagocytosed material in the epidermal area, the basal cells of the epidermis appeared elongated having vesicular nucleus and cytoplasm rich with cell organelles with dilatation of the intercellular spaces and presence of neutrophils in state of lysis also, there were fibrocyts and bundles of collagen fiber.

After 14 days, light micrograph examination of the control group wound area showed the skin formed by epidermis of striated squamus keratinized epithelium and dermis formed by collagenous connective tissue. The keratinized layer lamellated and cells of the stratum granulosem contain deeply stained granules. Electron micrograph showed the dermis formed by fibrocytes and bundles of collagen fibers and the basal cell layer of epidermis of cuboidal type having large vesicular nucleus and its chromatin clumped at the periphery. In the basal cell layer and stratum spinosum and stratum lucidum, the intercellular spaces and connections dilated. The stratum granulosum contains variable size electron dens hyaline granules and the keratinized layer was lamellated.

In panthenol group, light micrograph showed complete regeneration of both epidermal epithelial covering and the dermal connective tissue. Electron micrograph of the wound site showed epidermal cell layers of the skin, basal cells, stratum spinosium, stradum lucedium and dermal 
connective tissue. There were homogenous electron dens hyaline granules in the stratum lucedium of the epidermis and lamellated stratum kornium. In the dermal connective tissue, fibrocytes and bundles of collagen fibers with presence of variable membranous variable size vacuoles contain light electron material in the cytoplasm of the fibroblastic cells.

In helarium group, light micrograph showed the epidermis at the two edges of the wound and in between area of inflammatory cell reaction. Electron micrograph showed edema, presence of neutrophils, macrophages and bandulls of collagen fibers. Active basal cells of the epidermis having large vesicular nucleus and cytoplasm rich with cell organelles, there were edema and dilatation of the intercellular spaces of the epidermal cells.

Table (1): Losing wound area $\left(\mathrm{mm}^{2}\right)$ in control, panthenol and helarium groups during 14 days of treatment

\begin{tabular}{|c|c|c|c|c|c|}
\hline \multirow{2}{*}{ Groups } & \multicolumn{5}{|c|}{ Wound area $\left(\mathbf{m m}^{\mathbf{2}}\right)$} \\
\cline { 2 - 6 } & $\mathbf{0}$ & $\mathbf{1}$ & $\mathbf{7}$ & $\mathbf{1 4}$ & \\
\cline { 2 - 6 } & $\mathbf{0}$ & $19.0 \pm 0.44^{\mathrm{a}}$ & $14.4 \pm 0.64^{\mathrm{a}}$ & $3.40 \pm 0.36^{\mathrm{a}}$ & \\
\hline control & $21.4 \pm 0.66^{\mathrm{a}}$ & $18.4 \pm 0.28^{\mathrm{a}}$ & $12.3 \pm 0.49^{\mathrm{b}}$ & $1.80 \pm 0.31^{\mathrm{b}}$ & \\
\hline Panthenol & $21.2 \pm 0.59^{\mathrm{a}}$ & $18.1 \pm 0.27^{\mathrm{a}}$ & $14.7 \pm 0.69^{\mathrm{a}}$ & $3.43 \pm 0.52^{\mathrm{a}}$ & \\
\hline Helarium & $21.2 \pm 0.61^{\mathrm{a}}$ & $19.1 \pm 0.4$ &
\end{tabular}

Table (2): Losing wound contraction \% for control, panthenol and helarium groups during 14 days of treatment

\begin{tabular}{|c|c|c|c|c|}
\hline \multirow{2}{*}{ Groups } & \multicolumn{4}{|c|}{ Wound Contraction (\%) } \\
\cline { 2 - 5 } & \multicolumn{4}{|c|}{ Days } \\
\cline { 2 - 5 } & $\mathbf{0}$ & $\mathbf{1}$ & $\mathbf{7}$ & $\mathbf{1 4}$ \\
\hline control & 0 & 11 & 43 & 84 \\
\hline Panthenol & 0 & 14 & 31 & 84 \\
\hline Helarium & 0 & 10 & 42 \\
\hline
\end{tabular}

Wound contraction $\%=$ (area at first day-area at biopsy day) / (area on first day) $\times 100$ 


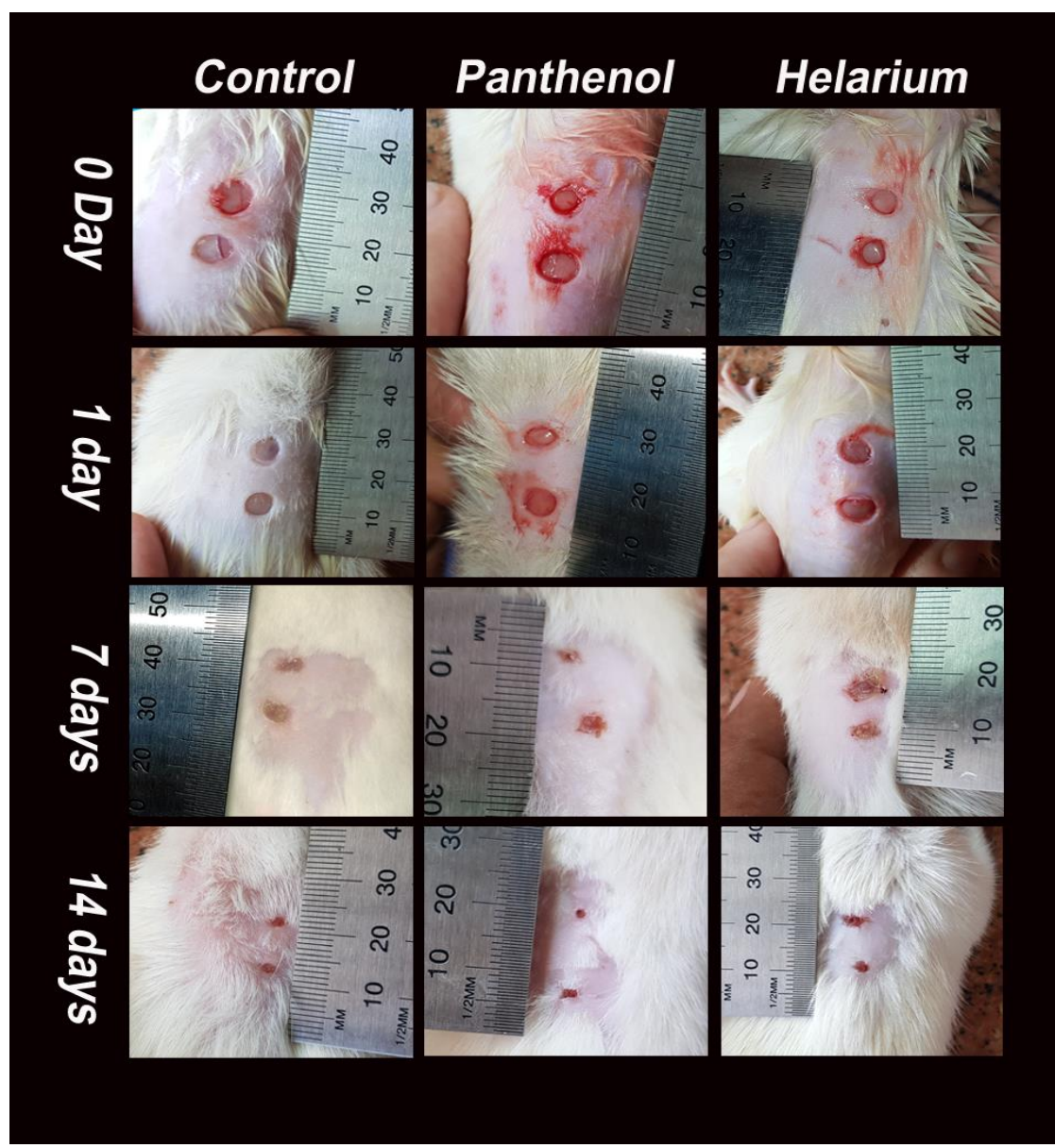

Fig. 2: showing macroscopic assessment of the healing process of the losing wound after 1,7 and 14 days from wounding day ( 0 day). The figures compare the healing progression in normal (untreated) group and in panthenol and helarium topically treated groups. 


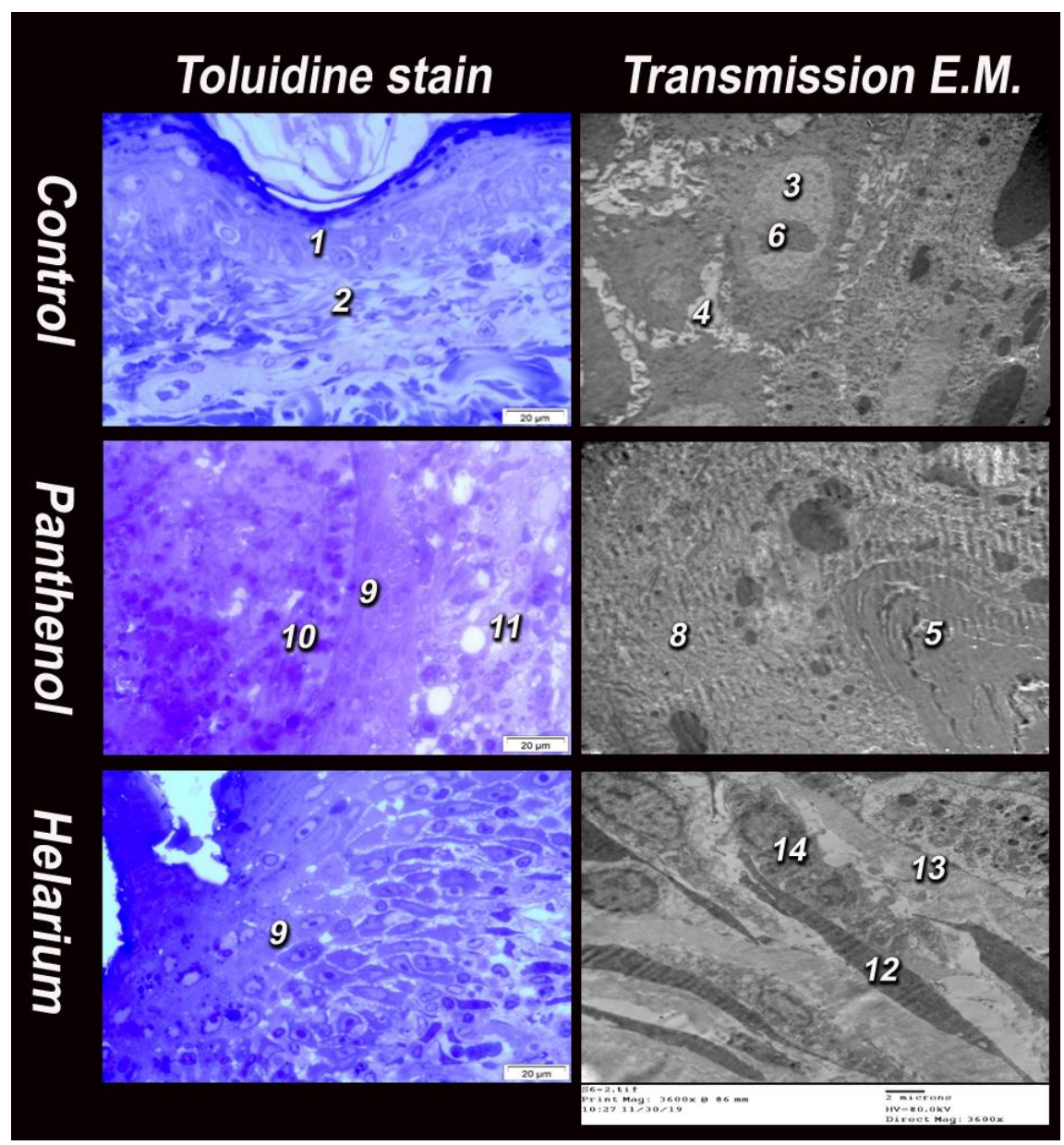

Fig. 3: Showing healing progress of the losing wound after 7 days from the topical application of either panthenol or helarium. Imaging was done using either light microscopy with toluidine blue stain (left side) or transmission electron microscope (right side).

Numbers point to: stratum squamosum epithelium (1) basal cell layer (2), large vesicular nucleus (3), wide intercellular spaces (4), thin laminated keratin layers (5), prominent nucleolus (6), dens keratohyaline (7), hyaline granules (8), regenerated epidermal epithelium (9) reacted cellular infilteration (10), dermal connective tissue (11), fibrocytes (12), bundells of collagen fibers (13), lysosomes and phagocytosed materials (14). 


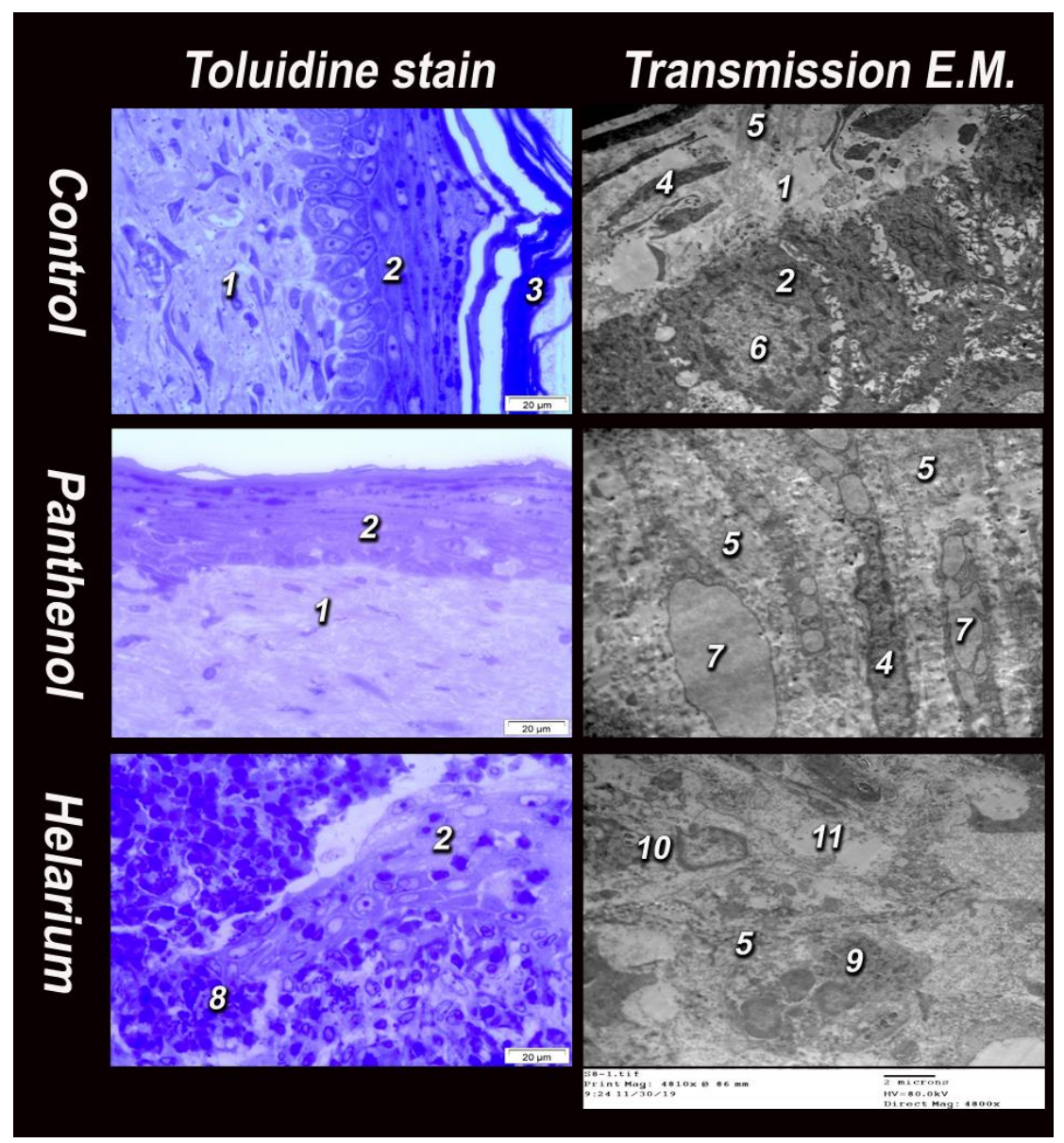

Fig.4: Screening of the healing progress of the losing wound after 14 days of the topical medications with either panthenol or helarium. Imaging was done using either light microscopy with toluidine blue stain (left side) or transmission electron microscope (right side).

Numbers point to: dermis (1), epidermis (2), keratinized layer (3), fibrocytes (4), collagen fibers (5), large vesicular nucleus (6) light electron material in the cytoplasm of the fibroblastic cells (7), cellular reaction (8), neutrophil cells (9), macrophages (10) and edema (11).

\section{Discussion:}

Skin is the largest and the most essential organ of the body as it plays a crucial role in maintaining body homeostasis. The wound healing process is a vital activity for the repair and regeneration of tissues and functions that have been harmed or damaged (Guo and Dipietro, 2010).

Many previous experiments used natural products for treatment of wounds (Muhammad and Muhammad, 2005).

In the present study, the effects of helarium and panthenol on 
excisional wound healing were evaluated. A significant healing was noticed with the individual application of helarium and panthenol but the effect of panthenol was more obvious than helarium. These findings may owe to anti-inflammatory and antiproliferative effects of panthenol (Kozlovsky et al., 2007). In this study, we used a wound area calculation method that was described by Hammad et al. (2011). In this method, digital pictures have been magnified by the computer to assign the wound boundaries and calculate the surface area using Image J software. This diminishes the effect of human error. According to our macroscopic results, the wound dimensions were significantly reduced over time with both treatments; panthenol effects were superior to helarium.

Wound healing is a complicated process that consists of four phases: homeostasis, inflammatory phase, a proliferation phase, and tissue remodeling phase (Werner and Grose, 2003 and Guo and Dipietro, 2010). In the phase of homeostasis started soon after wounding by vascular constriction and fibrin clot formation. The clot and wound tissue liberate pro-inflammatory cytokines and growth factors. Infilteration of platelets, neutrophils, macrophages, and lymphocytes in the wound area occurs in the inflammatory phase. Neutrophils are responsible for clearance of microbes and cellular debris. Macrophages release cytokines that encourage the inflammatory response by activating other leukocytes. Macrophages are also responsible for removal of apoptotic cells (including neutrophils) then stimulates keratinocytes, fibroblasts, and angiogenesis to help tissue regeneration (Meszaros et al., 2000; Mosser and Edwards, 2008). T-lymphocytes migration to the wound is delayed following the inflammatory cells and macrophages. In the proliferative phase, the number of fibroblasts and endothelial cells increased and help in capillary growth, collagen formation, and the development of granulation tissue. In the final remodeling phase fibroblasts produce extracellular matrix and collagen. Wound contraction all over the wound-healing process is mediated by contractile fibroblasts (Gosain and DiPietro, 2004; Campos et al., 2008; Guo and Dipietro, 2010 and Firat et al., 2014).

The edges of lose wound are not in contact with each other, so contraction and epithelization steps are important for the restoration process. The obtained results showed that daily topical application of panthenol gel and helarium cream enhanced contraction and reduced the epithelization period of the experimental wound. Contraction of wound area occurs at the healthy skin surrounding the wound, a 
process that is mediated by myofibroblasts while epithelialization includes the migration proliferation of epithelial cells to the wound area (Cotran et al., 1994). Therefore, the effects of helarium and panthenol on the contraction and epithelialization of wounds suggest their possible promoting or enhancing effects of their component on the migration and proliferation of epithelial cells. Re-epithelialization is an essential step for final wound closure.

Panthenol and helarium were chosen in this study based on their anti-inflammatory, analgesic, antioxidant and wound-healing characters. Losing wound model provides a controlled epithelial defect that is large enough to induce a full healing process. Two weeks were enough duration to show most of the expected changes.

Several studies proved that the topical application of panthenol enhance granulation, epithelial regeneration and promote wound healing (Heise et al., 2012; Camargo et al., 2011; Celebi et al., 2013; Ermis et al., 2013 and Proksch et al., 2017).

Helarium is composed of active ingredients known with its healing activities (honey, propolis, zinc oxide and chamomile), many researchers reported their promoting or accelerating wound healing effects that evaluated by the granulation tissue thickness, epithelialization and the dimensions of the wound (Awang-Dennis et al., 2006, Nayak et al., 2007; Bogdanov, 2009; Parolia et al., 2010; Kuropatnicki et al., 2013; Roohani et al., 2013; Yaghoobi et al., 2013; Martinotti and Ranzato, 2015; Molan and Rhodes, 2015 and Sforcin, 2016).

Using the microscopic examination (with transmission electron microscope) in this work demonstrated that panthenol and helarium groups showed regenerated epidermal epithelium with infiltration of inflammatory cells mainly neutrophils and macrophages in addition to dermal connective tissue with bundles of collagen fibers. In panthenol group, light micrograph of the site of the wound showed complete regeneration of both epidermal epithelial covering and the dermal connective tissue while, transmission electron micrograph of the regenerated epidermis showed presence of the homogenous electron dens hyaline granules in the stratum lucedum of the epidermis and lamellated stratum kornium after 14 days of treatment. These results came in agreement with (Enbar et al., 2002, Nayak et al., 2007, Parolia et al., 2010, Kuropatnicki et al., 2013, AbuSeida, 2015, Proksch et al., 2017 and Abbas et al., 2019).

Macroscopically, one remedy (panthenol) significantly enhanced healing process while the other (helarium) was nearly parallel to control. Based on that, apparent judgment of wound age might not 
be trusted enough so, microscopic examinations (light and electron) were our alternatives to find some ultra-structure features (fibroblast, macrophage and neutrophil infiltration as well as hyaline and collagen formation) that could be strongly used as milestone for estimation of wound age especially in treated wounds.

\section{Conclusion:}

From the obtained results in this study we can conclude that the promoting wound healing effects of panthenol and helarium were almost parallel but there was rapid shrinkage of wound area revealed in rats treated with panthenol compared with control and helarium. Results suggest that the wound healing could be accelerated by using these medications which consequently leads to inaccurate forensic judgment concerning wound age.

\section{Ethical Statement:}

This study was conducted in accordance with the guiding principles of the Scientific Ethical Committee, Faculty of Veterinary Medicine, Suez Canal University. Conflict of Interests:

Authors stated that they have no financial, professional or personal conflict of interests.

\section{References:}

Abbas S, Mahmoud S M, Abdou R H, Elhady K A. (2019): Considering Heal Promoters in
Estimating Wound Age in Rats. European $\mathrm{J}$ of Scientific Exploration. Vol. 2(2). 1-17.

Abu-Seida A. M. (2015). Effect of Propolis on Experimental Cutaneous Wound Healing in Dogs. Veterinary medicine international, 672643.

Astin JA, Pelletier KR, Marie A, Haskell WL. (2000). Complementary and Alternative medicine use among elderly persons: One year analysis of Blue Shield medicare supplement. J Gerontol, 55:M4- M9.

Awang-Dennis, VC. Taylor and Francis group (2006). New York: CRC Press. The herbs of Choice: The therapeutic use of Phytomedicinals; p. 292.

Biro, K;Thaci, D;Ochsendorf, FR; Kaufmann, R. andBoehncke, WH. (2003): "Efficacy of dexpanthenol in skin protection against irritation: a double-blind, placebo-controlled study". Contact Dermatitis. 49(2):80-4.

Bogdanov S. (2009). Beeswax: uses and trade. In: Bogdanov S, The Beeswax Book. Product Science; 11-12.

Bozzola. J. and Russell, L (1991) Electron microseopy principles and techniques for biologists: Jones and Bartlitt publishers 20 park plasa Boston Ma o 2116

Camargo FB Jr, Gaspar LR, Maia Campos PM. (2011). Skin moisturizing effects of 
panthenolbased formulations. $\mathbf{J}$ Cosmet Sci; 62:361-70.

Campos AC, Groth AK, Branco AB. (2008). Assessment and nutritional aspects of wound healing. Curr Opin Clin Nutr Metab Care 11:281-288.

Celebi S, Tepe C, Yelken K, Celik O. (2013). Efficacy of dexpanthenol for pediatric posttonsillectomy pain and wound healing. Ann Otol Rhinol Laryngol; 122:464-7.

Chang A, Dearman B, Greenwood J. (2011): A Comparison of Wound Area Measurement Techniques: Visitrak Versus Photography. Eplasty. 11: e18.

Cohen K, Robert F, Dorne D, Yagar R, Isaac L, Wornum III. (2005): Crosslamd wound care and wound healing/Schwartz, Shires, SPENCER Daly. Fischer, galloway/ principle of surgery. 7th ed. New York: MC Graw-hill; p. 263-6

Cotran R, Kumar V, Robbins S, Schoen F. (1994). Inflammation, and Repair. In: Robbins Pathologic Basis of Disease, 5th Edn, W.B. Saunders Company, Pennsylvania; 5: 51-92.

Ebner F, Heller A, Rippke F, Tausch I. (2002). Topical use of dexpanthenol in skin disorders. Am J Clin Dermatol; 3: 427-433.

Ermis H, Parlakpinar H, Gulbas G, (2013). Protective effect of dexpanthenol on bleomycininduced pulmonary fibrosis in rats.
Naunyn Schmiedebergs Arch Pharmacol; 386: 1103-1110.

Eshghi, F., Hosseinimehr, SJ., Rahmani, N., Khademloo, M., Norozi, MS., and Hojati, O. (2010)."Effects of Aloe vera cream on posthemorrhoidectomy pain and wound healing: results of a randomized, blind, placebo-control study". J Altern Complement Med. 16:647.

Firat ET, Dag A, Günay A, Kaya B, Karadede MI, Ersoz Kanay B. (2014). The effect of low-level laser therapy on the healing of hard palate mucosa and the oxidative stress status of rats. J Oral Pathol Med; 43:103-10.

Gehring W. and Gloor M. (2002): Effect of topically applied dexpanthenol on epidermal barrier function and stratum corneum hydration, Arzneimittelf, 50, 659663.

Gosain A, DiPietro LA. (2004). Aging and wound healing. World J Surg 28:321-326.

Grellner, W., \& Madea, B. (2007)."Demands on scientific studies: Vitality of wounds and wound age estimation." Forensic Science International, 150-154.

Guo S, Dipietro LA. (2010): Factors affecting wound healing. J Dent Res. 89 (3): 219 -229.

Hall, L., Clarke, K., Trim, C., (2001). In: Saunders, W.B. (Ed.), Anaesthesia of Birds, Laboratory Animals and Wild Animals, 10th 
ed. Harcourt Publishers Limited, England.

Hammad HM, Hammad MM, Abdelhadi IN, Khalifeh MS. (2011). Effects of topically applied agents on intra-oral wound healing in a rat model: a clinical and histomorphometric study. Int J Dent Hyg; 9:9-16.

Heise R, Skazik C, Marquardt Y, Czaja K, Sebastian K, Kurschat P, Gan L, Denecke B, Ekanayake-Bohlig S, Wilhelm K.P, Merk HF and Baron JM. (2012). Dexpanthenol modulates gene expression in skin wound healing in vivo. Skin pharmacol Physiol; 25:241-8.

Jull AB, Walker N, Deshpande S. (2013). Honey as a topical treatment for wounds. Cochrane Database Syst Rev. 2:CD005083.

Kozlovsky A, Artzi Z, Hirshberg A, Israeli-Tobias C, Reich L. (2007). Effect of local antimicrobial agents on excisional palatal wound healing: a clinical and histomorphometric study in rats. J Clin Periodontol ;34:164-71.

Kuropatnicki A.K., Szliszka E., Krol W. (2013). Historical aspects of propolis research in modern times.

Evidence-Based Complement. Alternat. Med.

Langemo D, Anderson J, Hanson D, Hunter S, Thompson P. (2008): Measuring wound length, width, and area: which technique? Adv Skin Wound Care. 21(1):42-5; quiz 45-7.
Martinotti S., Ranzato E. (2015). Propolis: a new frontier for wound healing. Burns Trauma, 3, p. 9

Meszaros AJ, Reichner JS, Albina JE. (2000), Macrophageinduced neutrophil apoptosis. J Immunol 165:435-441.

Molan P, Rhodes T. (2015): Honey: A Biologic Wound Dressing. Wounds. 27(6): 141-51.

Morton, LM., \& Phillips, TJ. (2016). "Wound healing and treating wounds: Differential diagnosis and evaluation of chronic wounds". Journal of the American Academy of Dermatology. 74 (4): 589-605.

Mosser DM, Edwards JP. (2008). Exploring the full spectrum of macrophage activation. Nat Rev Immunol 8:958-969.

Muhammad HS, Muhammad S. (2005): The use of Lawsoniainermis Linn. (Henna) in the management of burn wound infections. Afr J Biotechnol.

Na, Li., Qiuxiang, Du., Rufeng, Bai., and Junhong, Sun. (2018). "Vitality and wound-age estimation in forensic pathology": review and future prospects, Forensic Sciences Research.

Nayak BS, Raju SS, Rao AV. (2007): Wound healing activity of Matricaria recutita L. extract. J Wound Care. 16: 298-302.

Ohshima, T. (2000)."Forensic Wound Examination. "Forensic Science International,153-164. 
Parolia A., Thomas M.S., Kundabala M., Mohan M. (2010). Propolis and its potential uses in oral health. Int. J. Med. Med. Sci., 2, pp. 210-215

Pawlak, K.; Mysliwiec, M.; Pawlak, D. (2012): The alteration in $\mathrm{Cu} / \mathrm{Zn}$ superoxide dismutase and adhesion molecules concentrations in diabetic patients with chronic kidney disease: The effect of dialysis treatment. Diabetes Res. Clin. Pract. 98, 264-270.

Proksch E., de Bony R., Trapp S. et al. (2017): "Topical use of dexpanthenol: a 70th anniversary article," Journal of Dermatological Treatment, vol. 28 , no. 8 , pp. $766-$ 773.

Roohani, N.; Hurrell, R.; Kelishadi, R.; Schulin, R. (2013): Zinc and its importance for human health: An integrative review. J. Res. Med. Sci. 18, 144-157.

Sforcin, J.M. (2016): Biological properties and therapeutic applications of propolis. Phytother Res, 30, 894- 905.

Sforcin, JM; Bankova, $\mathrm{V}$ and Kuropatnicki, AK. (2017): Medical benefits of honeybee products. Evid Based Complement Alternat Med. Vol; 2017: 2702106, doi: 10.1155/2017/2702106.

Steel R.G.D. and Torrie J. (1981). principles and procedures of Statistics. Abiometric Approach 2nd Edition.

Sung S. H., Choi G. H., Lee N. W., Shin B. C. (2017). External use of propolis for oral, skin, and genital diseases: a systematic review and meta-analysis EvidenceBased Complement. Alternat. Med. Sung, S. H., Choi, G. H., Lee, N. W., \& Shin, B. C. (2017). External Use of Propolis for Oral, Skin, and Genital Diseases: A Systematic Review and Meta-Analysis. Evidence-based complementary and alternative medicine: eCAM, 2017, 8025752.

Toreti, V.C., Sato, H.H., Pastore, G.M. and Park, Y.K., (2013). Recent progress of propolis for its biological and chemical compositions and its botanical origin. Evidence-Based Complementary and Alternative Medicine, vol. 697390, pp. 1-13.

Veiga R., De Mendonça S., Mendes P., Paulino N., Mimica M., Lagareiro Netto A., Lira I., López B.C., Negrão V., Marcucci M. (2017). Artepillin C and phenolic compounds responsible for antimicrobial and antioxidant activity of green propolis and Baccharis dracunculifolia DC. J. Appl. Microbiol., 122, pp. 911-920. Wan, Li-Mei., Tan, J., Wan, Shan-He., Meng, Dong-Mei., and Yu, Peng-Jiu. (2016)."Antiinflammatory and Anti-oxidative Effects of Dexpanthenol on Lipopolysaccharide Induced Acute Lung Injury in Mice".Inflamation. Volume 39, Issue 5, pp 1757-1763.

Werner S, Grose R. (2003). Regulation of wound healing by 
growth factors and cytokines. for Clinical Use of Honey in Physiol Rev.

Wound Healing as an Anti-

Wijesinghe $M$, Weatherall $M$, Perrin K, Beasley R (2009). Honey in the treatment of burns: a systematic review and metaanalysis of its efficacy. $\mathrm{N}$ Z Med J. ;122(1295):47-60.

Yaghoobi, R., Kazerouni, A., \& Kazerouni, O. (2013): Evidence bacterial, Anti-inflammatory Antioxidant and Anti-viral Agent: A Review. Jundishapur journal of natural pharmaceutical products, 8 (3), 100-104.

Zumla A, Lulat A (1989). Honey-a remedy rediscovered. J R Soc Med. 82(7): 384-5.

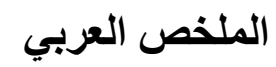

العلاج الموضعي للجروح ربما يضلل التقدير الطبي الشرعي

$$
\begin{aligned}
& \text { رانيا حلمي عبده \& شيرين محمد محمود }
\end{aligned}
$$

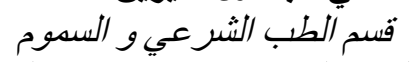

$$
\begin{aligned}
& \text { كلية الطب البيطرى - جامعة قناة السوبس النس }
\end{aligned}
$$

تمثل الجروح مشكلة كبيرة ومهمة جدًا في تقارير الطب الثرعي وتأتي أهميتها الطبية الثرعية

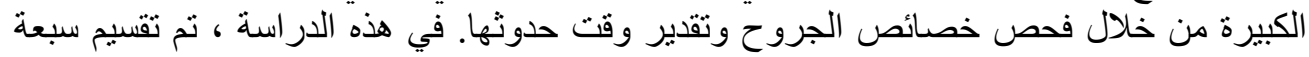

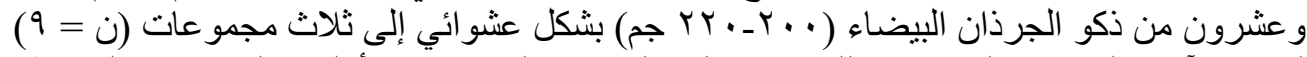

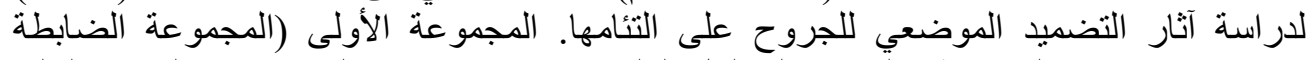

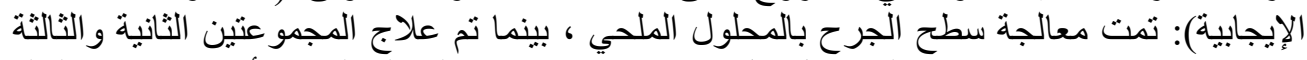

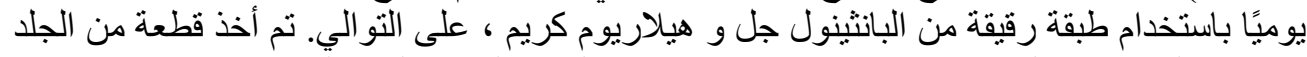

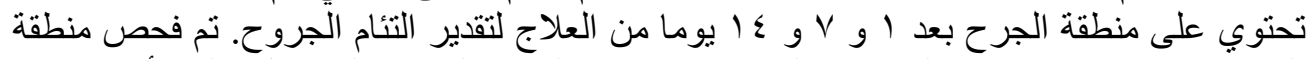

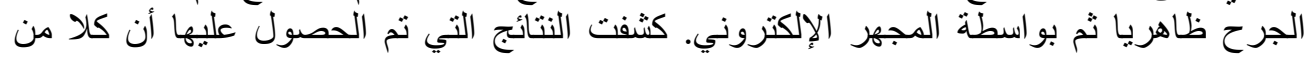

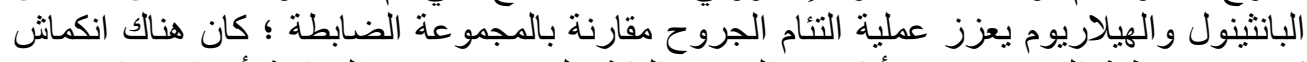

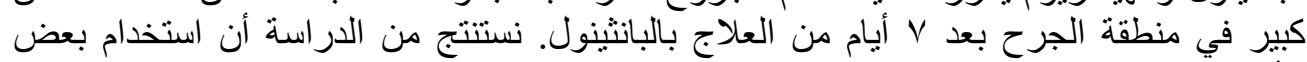

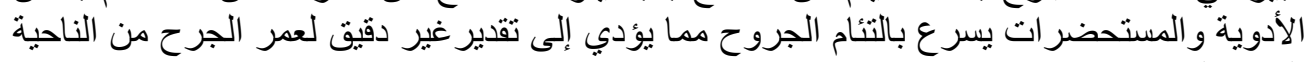

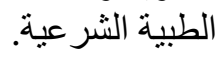

